\title{
Comportamento de agregação noturna dos machos de Actinote surima surima (Schaus) (Lepidoptera, Heliconiinae, Acraeini) ${ }^{1}$
}

\author{
Márlon Paluch ${ }^{2,3}$, Mirna M. Casagrande ${ }^{2,4}$ \& Olaf H. H. Mielke ${ }^{2,4}$ \\ 1 Contribuição número 1538 do Departamento de Zoologia, Universidade Federal do Paraná. \\ ${ }^{2}$ Departamento de Zoologia, Universidade Federal do Paraná. Caixa Postal 19020, 81531-980 Curitiba, Paraná, Brasil. \\ ${ }^{3}$ Bolsista de Doutorado do CNPq. \\ ${ }^{4}$ Pesquisador do CNPq.
}

\begin{abstract}
Male sleeping aggregation behavior of Actinote surima surima (Schaus) (Lepidoptera, Heliconiinae, Acraeini). This article registers nocturnal aggregation behaviour of the males of Actinote surima surima (Schaus, 1902) studied at the city of Curitiba, Paraná, Brazil. There is little knowledge on the ethology and ecology of the adults of Actinote Hübner, [1819], considering the great number of species registered, approximately 26 species and 36 subspecies nominated for the Neotropical region. Territorial roosting and mating system are comparatively discussed with the genus Heliconius Kluk, 1780.

KEY WORDS: Heliconius, Neotropical, roost.
\end{abstract}

RESUMO. Este artigo registra o comportamento de agregação noturna de machos de Actinote surima surima (Schaus, 1902), estudado na cidade de Curitiba, Paraná, Brasil. A etologia e ecologia dos adultos de Actinote Hübner, [1819] são pouco conhecidas perante o grande número de espécies registradas, aproximadamente 28 espécies e 36 subespécies descritas para a região Neotropical. Poleiros gregários, defesa territorial e o processo de cópula são discutidos comparativamente com o gênero Heliconius Kluk, 1780.

PALAVRAS CHAVE. Heliconius, neotropical, poleiros.

A tribo Acraeini (LAMAs 2004) compreende na região Neotropical os gêneros: Altinote Potts, 1943; Abananote Potts, 1943 e Actinote Hübner, [1819], sendo que apenas o último possui representantes no território brasileiro.

Mielke (1994) lista 10 espécies de Actinote para Curitiba e seus arredores, destas pouco se conhece a respeito da sua bionomia. PALuch et al. $(1999,2001)$, apresentaram estudos do desenvolvimento dos imaturos de Actinote surima surima (Schaus, 1902) e Actinote carycina Jordan, 1913, respectivamente, suas relações de herbivoria em algumas regiões do Paraná, descrição morfológica geral dos imaturos e estudo da quetotaxia da larva de $1^{\circ}$ estádio e alguns dados a respeito do comportamento dos imaturos. Brown \& Francini (1990) citam que os ovos, larvas, pupas e adultos de Acraeini americanos são de coloração conspícua, gregários e raramente sofrem pressão de predadores vertebrados ou invertebrados.

Informações sobre agregações para o descanso noturno em Acraeini foram relatadas primeiramente por CARPENTER (1931), com indivíduos de quatro espécies de Acraea Fabricius, 1807 que se reuniam para pernoitar.

Algumas espécies pertencentes à tribo Heliconiini apresentam os hábitos etológicos dos adultos bem elucidados. MALLET (1986) relata a formação dos "gregarious roosting" (poleiros gregários) em muitas espécies de Heliconius Kluk, 1780: H. erato (Linnaeus, 1758), H. charitonia (Linnaeus, 1767), H. sapho hewitsoni Hewitson, 1875, H. melpome (Linnaeus, 1758), H. cydmo pachinus Salvin, 1871, H. ismenius Latreille, [1817] e $H$. hecale (Fabricius, 1776); grupo irmão de Acraeini segundo Penz \& Peggie (2003).

Ruszczyk et al. (2004), usando como exemplo Eurema elathea (Cramer, 1777) (Pieridae, Coliadinae)) discutem o significado ecológico e evolutivo do polifenismo e das agregações noturnas.

\section{MATERIAL E MÉTODOS}

Os exemplares de A. surima surima utilizados para este estudo são provenientes do "Capão do Biotério" do Centro Politécnico da Universidade Federal do Paraná em Curitiba, Paraná, Brasil, 900 - 950m. O capão encontra-se atrás do Setor de Ciências Biológicas, margeado pelas rodovias BR 116 e BR 277 e é caracterizado como uma ilha de mata secundária de Araucária, como também o são grande parte dos parques urbanos de Curitiba. Este em especial apresenta uma grande quantidade de Eupatorium intermedium DC (PALUCH et al. 1999) uma das plantas hospedeiras de A. surima surima. 
Larvas foram mantidas em gaiolas juntamente com folhas e ramos da planta hospedeira. As pupas e os adultos foram mantidos em casa de vegetação.

Estudos de ecologia e etologia de borboletas são fundamentados em trabalhos de campo que dependem de capturar, marcar, soltar e recapturar indivíduos M.R.R. ("mark-releaserecapture"), metodologia utilizada por MoRTON (1984) em seus artigos com Melanargia galathea (Linnaeus, 1758) (Nymphalidae, Satyrinae), onde mostra os efeitos da marcação e manipulação sobre a freqüência de recaptura de borboletas. Nesse estudo utilizou-se uma adaptação do método M.R.R. na tentativa de compreender a dinâmica existente nas agregações de Actinote.

Usou-se uma mistura de tinta "nankin" comercial atóxica, contendo 50\% de tinta branca e 50\% vermelha, resultando na cor rosa. Todos os indivíduos foram marcados com algarismos arábicos em ordem crescente a partir da primeira emergência, foram anotados sexo, cópula em laboratório e datas (emergência, soltura e recaptura). Os machos receberam a numeração no ápice da asa anterior direita na face ventral, acima da célula discal, próximo ou sobre a faixa subapical amarela (Fig. 1), já as fêmeas receberam a marcação no ápice da asa posterior direita na área ventral próximo à margem. Para tanto, utilizou-se pincéis e presilhas de plástico montadas para prender apenas as asas fechadas em posição de repouso de maneira que permitisse a manipulação sem danos ao restante do corpo, pois conforme o observado por MoRTon (1984), os indivíduos pouco manipulados tiveram uma freqüência de recaptura superior. A secagem da tinta ocorre nos instantes em que o inseto permanece em comportamento de tanatose, notável para as espécies de Actinote. Indivíduos capturados, naturais da área de experimento, não foram marcados.

Os indivíduos, sempre que possível, foram marcados e soltos no mesmo dia de sua emergência e logo após terem suas asas totalmente esticadas e "secas", porém alguns exemplares, permaneceram até no máximo dois dias em casa de vegetação alimentados com solução 10\% de mel de abelha, esta permanência foi necessária quando nos dias de soltura havia muita chuva.

Foram feitas observações e recapturas no campo com auxílio de rede entomológica das 16:00 às 18:00 h (horário de verão - Brasília) durante 15 dias intercalados, salvo exceções dos dias chuvosos, abrangendo o período de vôo da espécie em Curitiba entre novembro e dezembro de 2002, ou a segunda geração.

Outra metodologia utilizada durante o pico populacional de abril de 2003, primeira geração, em Curitiba, foram observações e recapturas de indivíduos provenientes do campo, entre 15:00 e 17:00 h. Neste caso, a marcação foi realizada após a acomodação de todos os indivíduos que compunham um determinado aglomerado. As marcações foram feitas por grupos, todos os indivíduos de um mesmo aglomerado ou poleiro receberam a mesma marca (um ponto rosa na face ventral da asa posterior direita) diferente da marcação do segundo grupo e assim sucessivamente. De modo a poder estudar a inter-relação entre os vários grupos formados, estes indivíduos não foram manipulados, apenas receberam suas marcas a partir de toques com pincéis de ponta fina embebidos em tinta nanquim não tóxica (rosa).

Dados a respeito da temperatura, umidade relativa média e precipitação diária de Curitiba, em novembro e dezembro de 2002, foram fornecidos pelo Instituto Metereológico SIMEPAR (Sistema Meterológico do Paraná), da estação de Curitiba, Paraná.

\section{RESULTADOS E DISCUSÃO}

\section{Habitat, plantas hospedeiras e distribuição temporal}

No local estudado A. surima surima apresenta dois períodos de vôo e conseqüente acasalamento, portanto bivoltina, com a primeira revoada do ano entre março/abril e a segunda entre novembro/dezembro. O habitat no litoral do Paraná são as restingas e outras áreas próximas onde ocorre Eupatorium casarettoi (Rob.) Steyermark (Asteraceae) assim como as outras plantas hospedeiras. Nos planaltos paranaenses o ambiente é caracterizado por clareiras e beiras de capões às margens da Floresta de Araucária, áreas com grande incidência de luminosidade solar, com abundância de Eupatorium intermedium DC, um arbusto típico nesse meio. As larvas possuem hábitos gregários até atingirem o tamanho aproximado de dois centímetros, no terceiro ou quarto estádio. No último estádio alimentam-se isoladamente nas folhas dos arbustos (РALuch et al. 1999).

Outras plantas são listadas como hospedeiras da espécie, Penz \& Francini (1996), além do Eupatorium intermedium citam Senecio brasiliensis Linnaeus, Mikania hirsutissima DC, Eupatorium buniifolium Hook. \& Arn, Symphiopappus reticulatus, Eupatoriun casarettoi (Asteraceae); e para ser estudada a possibilidade de Amaranthus hybridus L. (Amaranthaceae) como citado por BiEzAnKo et al. (1974).

Encontramos Mikania hirsutissima no município de Curitiba e no Parque Estadual Pico Paraná, nos municípios de Antonina e Campina Grande do Sul; utilizada como planta hospedeira de Actinote genitrix D'Almeida, 1922; Senecio bonariensis Hook. \& Arn foi a única espécie do gênero registrada até o momento nos Mananciais da Serra, município de Piraquara, próximo aos limites da capital e Serra da Baitaca, distrito de Borda do Campo, Quatro Barras, como planta hospedeira de Actinote mamita mitama (Schaus, 1902).

\section{Comportamento sexual e defesa de território}

Foram criadas até a fase adulta e soltas no campo 311 borboletas provenientes de sete lotes de larvas trazidas do "Capão do Biotério" quando estas se encontravam entre o segundo e o terceiro estádio, alimentando-se de E. intermedium, teoricamente sete lotes de diferentes posturas.

A soltura dos indivíduos no campo teve início com as primeiras emergências em 11.XI.2002 e seu término em 4.XII.2002, somando 23 dias de inclusões de indivíduos no ambiente. 
As observações etológicas e o esforço de recaptura tiveram início no dia 12.XI.2002 e seu término em 10.XII.2002, durante 15 dias intercalados, cobrindo todo o período de vôo na área do experimento.

Nos sete primeiros dias (11-17.XI.2002) registrou-se a emergência de 36 borboletas, 31 machos e 5 fêmeas; na segunda semana (18-24.XI.2002) foram 142 indivíduos, 86 machos e 56 fêmeas; na terceira semana (25.XI-1.XII.2002) foram 117 indivíduos, 28 machos e 89 fêmeas e nos últimos três dias mais 16 fêmeas, ao todo 145 machos e 166 fêmeas soltos no campo. Estes dados relacionados com os indivíduos machos recapturados no campo com no máximo sete dias após a soltura $(n=9)$, mostra a possibilidade de uma fêmea com menos de $24 \mathrm{~h}$ de vida adulta, copular com um macho da mesma "idade" ou com um macho de sete dias de vôo.

Treze machos copularam no laboratório, sendo que três destes foram recapturados após um, três e quatro dias da soltura no campo, defendendo território. Em laboratório um macho emergiu e copulou com uma fêmea no mesmo dia, realizando uma segunda cópula, no dia seguinte, com outra fêmea, deixando o tampão genital apenas na primeira, caracterizando esta estrutura como uma barreira física que na maioria das vezes garante a fecundação única de uma fêmea (Marshall 1901). Das duas fêmeas que copularam com o mesmo macho, as oviposições tiveram $100 \%$ de sucesso, apresentando todos os ovos embrionados com desenvolvimento normal das larvas. Essas observações corroboram a idéia de que os machos das espécies de Actinote podem copular mais de uma vez ao contrário do que suspeitava PALUCH et al. (2003), porém realmente podem depositar apenas um tampão genital, ou seja, na primeira cópula.

Muitas espécies de borboletas apresentam coloração conspícua exibida durante o vôo através de flashes de luz ultravioleta que servem de aviso na demarcação de seus territórios (BAKER 1983). Em Actinote surima surima o comportamento de defesa de território entre os machos consiste de demarcações de corredores nas clareiras de até $15 \mathrm{~m}$ de distância onde os indivíduos voam entre um e dois metros de altura, atacando várias espécies de lepidóptera inclusive os machos concorrentes, seguido de patrulhamento da área demarcada nos instantes seguintes; a estratégia do tipo "senta e espera" é adotada até que ocorra a invasão do seu território, sendo o ataque de caráter defensivo ou investigativo no caso de identificação de alguma fêmea. Este tipo de estratégia e território defendido é classificado por LOPES \& DE MARCO (2000), na revisão a respeito do comportamento territorial em insetos, como território sem recurso, ou seja, os machos defendem posições que não são associáveis a nenhum recurso direto defendido, com possível exceção da presença de fêmeas.

Alcock (1987) observou que os machos de Celaenorrhinus approximatus R.C.Williams \& Bell, 1940, Astraptes galesus cassius Evans, 1952 (Hesperiidae) e Mesosemia asa asa Hewitson, 1869 (Riodinidae) na Costa Rica, também defendem territórios do tipo sem recurso. Os machos permanecem pousados em deter- minados pontos que abrangem uma área " $\mathrm{X}$ " defendida durante vários dias pelos mesmos indivíduos através de manobras aéreas defensivas, porém os acasalamentos são raros nesses locais. Durante o experimento pode se observar dois machos defendendo seus respectivos territórios entre as 15:00 e 16:00 h (horário de verão - Brasília) durante três dias de vida, foram recapturados nos mesmos corredores, porém não foi registrado se os territórios eram mantidos após a cópula.

Espécies de borboletas com alta palatabilidade para predadores visualmente orientados tendem a demarcar seus territórios dentro de determinadas estratégias de sobrevivência, como exemplo, Caligo idomeneus (Linnaeus, 1758) (Nymphalidae) demarca seus territórios por pouco tempo antes do amanhecer (Freitas et al. 1997). Em A. surima espécie aposemática, com cores conspícuas e propriedades impalatáveis (Brown \& FrancinI 1990) a demarcação pode ser feita em horários de plena atividade da avifauna, em todos os exemplares capturados e recapturados no campo nenhum apresentou marcas que indicassem agressões por predadores vertebrados.

A cópula não apresenta corte e sim captura da fêmea, podendo até mesmo ocorrer o pareamento do casal no chão (Marshall 1901). Porém outros aspectos ainda não estudados, devem estar envolvidos no reconhecimento intraespecífico, pois as fêmeas da maioria das espécies de Actinote são muito similares visualmente. Talvez as fêmeas após se tornarem receptivas à cópula se utilizem de algum feromônio de identificação intraespecífico ou a cópula interespecifica se torne inviável, devido a incompatibilidade morfológica de genitálias.

Durante a cópula, se o casal for incomodado por algum fator, é a fêmea que conduz o vôo para outro local, sendo que o macho permanece "pendurado" pela junção das genitálias e com as asas em posição de repouso. Em abril de 2003 observou-se um casal em cópula e que aproximadamente três minutos após o inicio do pareamento, foi atacado por um segundo macho resultando na separação do casal, a fêmea não chegou a receber o tampão genital, continuando então disponível para uma nova cópula, e mostrando um comportamento mais agressivo do que de algumas espécies de Acraea, grupo irmão da região Etiópica. A exemplo disso Sourakov \& EMmel (1997) observaram um casal de Acraea epaea (Cramer, 1779) em cópula com um segundo macho pousado sobre as asas da fêmea durante o processo, na espera que a fêmea se torne disponível para um segundo acasalamento.

Todas as fêmeas registradas estavam acomodadas sozinhas em arbustos e árvores para passar a noite. Recapturadas, com vida variando entre dois e cinco dias, a maioria em flores de Asteraceae, não sendo muito freqüente em vôo como os machos em seus territórios. Treze fêmeas que foram soltas virgens, foram recapturadas entre a segunda e a terceira semana de soltura, com dois, três e quatro dias de vida e todas com tampão genital.

Em laboratório, nos treze pareamentos ocorridos, obteve-se todas as combinações possíveis entre machos e fêmeas

Revista Brasileira de Zoologia 22 (2): 410-418, junho 2005 
recém emergidas até dois dias de cativeiro, com um único pareamento entre indivíduos recém emergidos, ou seja, logo após as asas esticadas e secas. Nenhum pareamento foi registrado com fêmeas ou machos recém saídos das pupas com as asas ainda não esticadas.

O tempo de duração de pareamentos $(n=7)$ : variou de 81' a $107^{\prime}\left(\mathrm{X}=94^{\prime} 29^{\prime \prime}\right.$; $\left.\mathrm{DP}=8^{\prime} 7^{\prime \prime}\right)$.

\section{Método M.R.R. e dinâmica das agregações}

Na segunda quinzena de novembro de 2001 foram registradas as quatro primeiras agregações dos machos de Actinote surima com poleiros de 6, 7, 10 e 13 indivíduos machos (Figs 2 e 3 ) na cidade de Curitiba, o que levou a realização do experimento de marcações individuais, para se obter maiores informações a respeito da dinâmica destas agregações.

Foram observadas três agregações durante o experimento de novembro de 2002. A primeira no dia 20.XI.2002 com oito indivíduos dos quais quatro estavam marcados com as respectivas idades; um com um dia, dois com dois dias, um com três dias e quatro não estavam marcados, sendo indivíduos naturais do campo (Fig. 4).

A segunda, no dia 22.XI.2002 com sete indivíduos, cinco estavam marcados com as respectivas idades; um com dois dias, dois com três dias, um com quatro dias, um com cinco dias e dois não apresentavam marcas, e o indivíduo com quatro dias já havia sido observado junto à primeira agregação no dia 20.XI.2002 quando com dois dias de vida.

A terceira no dia 24.XI.2002 com 10 indivíduos dos quais oito estavam marcados com as respectivas idades; um com dois dias, dois com três dias, três com quatro dias e dois com cinco dias, sendo que um dos indivíduos com cinco dias foi observado junto à agregação do dia 22.XI.2002 quando tinha três dias de vida.

Os poleiros com maior número de indivíduos marcados, cinco e oito, foram observados após treze e quinze dias de emergência de adultos no laboratório quando havia 93 e 117 machos, respectivamente, soltos no campo. Nos dois primeiros poleiros registrados havia indivíduos das duas primeiras semanas de soltura, já no terceiro poleiro foram observados machos que emergiram apenas na segunda semana. Os últimos 28 machos soltos no campo na terceira semana não foram registrados em agregações. Dos machos que copularam em laboratório apenas um foi registrado na agregação do dia 24.XI.2002 com quatro dias de vida.

Na segunda quinzena de abril de 2003, na primeira revoada anual da espécie, através da metodologia de marcações por grupos foi possível levantar os seguintes dados (Fig. 5).

No dia 23.IV.2003 foram registrados oito machos em uma agregação, sendo que todos receberam a mesma marca, um ponto rosa ventralmente no ápice da asa anterior esquerda, "grupo 1".

No dia 24.IV.2003 foram registrados dois grupos; um grupo com sete indivíduos, destes, cinco receberam um ponto rosa ventralmente no ápice da asa anterior direita "grupo 2" sendo que os outros dois, já estavam marcados e portanto pertenci- am ao "grupo 1" do dia anterior. O outro grupo observado nesse mesmo dia era composto por cinco indivíduos, destes, quatro receberam um ponto rosa ventralmente na célula discal da asa posterior direita, "grupo 3", sendo que o quinto pertencia ao "grupo 1" do dia anterior.

No dia 26.IV.2003 foi registrado uma agregação de quatro indivíduos todos foram marcados compondo o "grupo 4", porém não foram mais vistos juntamente com os grupos 1, 2 e 3 em mais quatro dias de observações. Registrou-se também uma queda acentuada na atividade de vôo da espécie o que agrega dados à hipótese de saturação da planta alimentícia já que estes grupos foram acompanhados no final de abril de 2003 e a planta estava repleta de posturas em adiantado estado de embrionamento.

\section{Influência da temperatura, umidade do ar e precipita- ção diária sobre o comportamento dos adultos}

Os dados meteorológicos foram comparados com os resultados obtidos no campo, observou-se uma temperatura média variando entre $14.7{ }^{\circ} \mathrm{C}$ dia 13 e $24.3{ }^{\circ} \mathrm{C}$ dia 27 de novembro; a temperatura máxima variou entre $17.8^{\circ} \mathrm{C}$ dia 13 e 32.3 ${ }^{\circ} \mathrm{C}$ dia 24 de novembro; a temperatura mínima variou entre $11.8^{\circ} \mathrm{C}$ dia 13 e $20.3{ }^{\circ} \mathrm{C}$ dia 27 de novembro; a umidade relativa média variou entre $52.5 \%$ dia 12 e $89.6 \%$ dia 28 de novembro; a precipitação diária variou entre $0.0 \mathrm{~mm}$ durante 11 dias do experimento até $44.0 \mathrm{~mm}$ dia 28 de novembro (Fig. 7).

Quanto às temperaturas, foram típicas de verão, sendo que no dia mais frio, 13 de novembro, quando a mínima foi de 11.8 , a máxima de 17.8 e a média 14.7 ; haviam poucos indivíduos soltos no campo, porém observou-se uma pequena atividade de vôo entre as outras quatro espécies de Actinote que ocorrem na área. À medida que as borboletas foram emergindo as atividades se tornaram freqüentes a partir das 09:00 h (horário em que os machos se separam das agregações pela manhã) até a formação dos poleiros, próximo às 17:00 h, sendo que as temperaturas médias se mantiveram relativamente constantes, sem grandes variações durante o período de pico populacional entre os dias 18 de novembro e 01 de dezembro, a temperatura média variou entre $16.8^{\circ}$ e $24.3^{\circ}$ quando ocorreu a emergência de 259 borboletas entre machos e fêmeas.

Assim como a temperatura, a umidade do ar durante o pico populacional manteve-se constante variando entre $70.3 \%$ dia 20 e $89.6 \%$ dia 28 de novembro.

Nos dias 15, 26, 28 de novembro e 5 de dezembro, uns dos mais chuvosos durante o experimento; quando as precipitações foram de 17.6, 15.0, 44.0, $27.2 \mathrm{~mm}$ respectivamente, observaram-se borboletas interrompendo suas atividades de alimentação, defesa de território e captura de fêmeas, para se proteger da chuva e do vento durante o final e meio da tarde; não foi observada a formação de nenhum poleiro, somente borboletas de ambos os sexos se protegendo sozinhas na vegetação do capão, árvores e arbustos folhosos, sendo que dois casais permaneceram em cópula enquanto durou a precipitação. Geralmente as chuvas de final de tarde faziam com que as borboletas permane- 


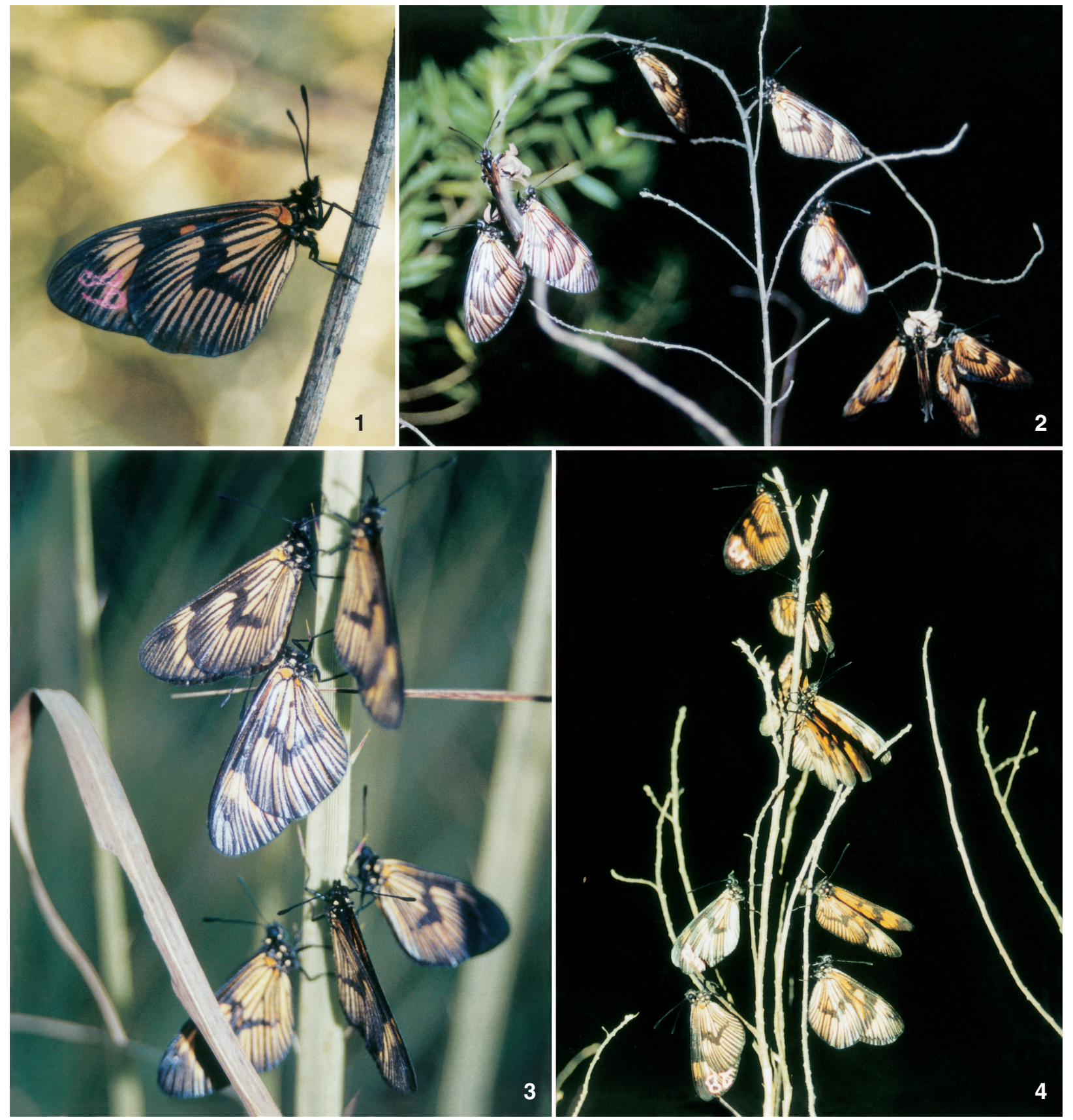

Figuras 1-4. Actinote surima surima: (1) vista lateral do macho, detalhe da marca individual no ápice da asa anterior direita; (2) poleiro de 10 indivíduos machos encontrados a $40 \mathrm{~cm}$ do solo; (3) poleiro de seis indivíduos em bromeliácea de solo; (4) poleiro de oito indivíduos dos quais quatro marcados, os demais naturais do campo.

cessem em seu abrigo até o próximo dia, certamente atuando como uma barreira para formação das agregações noturnas.

Os três poleiros observados ocorreram nos dias 20, 22 e 24 de novembro quando apenas uma precipitação de $0.4 \mathrm{~mm}$ foi registrada no dia 24 .
Poleiros gregários: Heliconiini X Acraeini

MALLET (1986) registrou a formação dos poleiros de espécies de Heliconius entre as 15:30h e 17:45 h no Parque Nacional Corcovado, Costa Rica e em Villa Garzón, Putumayo, Colômbia onde foram realizados os seus estudos. Os poleiros de $A$.

Revista Brasileira de Zoologia 22 (2): 410-418, junho 2005 
surima surima em Curitiba são formados a partir das 16:00 h (17:00 h no horário de verão) e os locais escolhidos podem ser desde galhos secos a $40 \mathrm{~cm}$ do solo até ramos de árvores frondosas (a maior freqüência foi para galhos secos sem folhas, 7 dos 11 observados), não havendo aparentemente uma preferência por tipo específico de planta, porém, curiosamente só registrou-se durante o período de observações, dois machos pernoitando sobre a planta hospedeira além de casais em cópula. Todos os locais escolhidos para a formação dos poleiros não tiveram uma freqüência de repetição, de maneira que, a cada dia um novo local pode ser escolhido, não se observou marcação específica ou química.

A formação dos poleiros se dá a partir de uma concentração de indivíduos em vôo em uma determinada área, provavelmente envolvida nas cercanias de seus territórios com a escolha aparentemente aleatória de um único macho que pousa em determinado local favorável. Este indivíduo após se acomodar, inicia o movimento das asas fornecendo estímulos visuais, denominados de "fanning" por Mallet (1986) para as espécies de Heliconius que consiste em abrir e fechar as asas, exibindo o seu padrão de coloração dorsal, no caso de $A$. surima bastante vistoso nas cores laranja e marrom enegrecido. $O$ movimento se repete com maior freqüência quando outros indivíduos se aproximam e se juntam ao primeiro realizando os mesmos movimentos envolvidos em um reconhecimento visual específico, pois ainda não se observaram formações interespecíficas, sendo que no local do experimento foram capturadas outras quatro espécies de Actinote voando no mesmo período. A partir das 17:30 h (18:30 h horário de verão) quando o sol se encontra em poente, os movimentos de abano das asas nos poleiros cessam. Algumas vezes, foram observados indivíduos que não conseguiram reconhecer a agregação, talvez devido à pouca luz, buscando então a vegetação próxima para pernoitar.

Este comportamento fortalece a hipótese de uma comunicação visual entre os machos para a formação de agregações, corrobora ainda a idéia de que o reconhecimento é feito através do padrão de coloração dorsal, de maneira que permite a realização das marcações das asas na face ventral sem interferir no reconhecimento específico, porém muitos machos ao deixarem um poleiro antes do por do sol se distanciando até 20 m, por alguma perturbação mecânica, podem se reaproximar nos minutos seguintes do mesmo poleiro sem que ocorram estímulos visuais de abano das asas dos machos empoleirados, sugerindo uma orientação visual do local ou ainda a possibilidade do envolvimento de feromônios de agregação.

Mallet (1986), observando as agregações de Heliconius, sugere que o abano das asas tenha a função de reconhecimento envolvendo sinais espécie-específicos, mesmo encontrando várias espécies agregadas em um determinado local estas formaram subgrupos específicos dentro do grupo interespecífico sugerindo que estes possuem meios de detecção coespecífica; segundo o autor este comportamento evolui de uma modificação da corte como já havia sido citado por Crane (1957 apud
Mallet 1986) estudando o comportamento de Heliconiini.

As agregações são pequenas em relação ao número de indivíduos encontrados em uma área, supondo que provavelmente este aspecto possa estar relacionado com o comportamento anti-social desenvolvido durante o dia, sendo que as formações somente se tornam possíveis a partir de invasões territoriais e ainda por indivíduos que provavelmente não tenham territórios estabelecidos, pois nas agregações foram registrados indivíduos com um a cinco dias de vida.

Quanto ao estudo da inter-relação entre os indivíduos dos poleiros, talvez se faça necessário uma amostragem mais ampla com um maior número de indivíduos machos soltos, porém dois indivíduos foram vistos fazendo parte de dois poleiros distintos, sendo que no primeiro ambos estavam com dois e três dias de vida, os mais "jovens" do grupo, já na segunda agregação eram os mais "velhos" do grupo com quatro e cinco dias de vida. A marcação por grupo realizada em abril corroborou a hipótese de que os poleiros não apresentam grupos definidos sendo as agregações aleatórias quanto ao local e aos indivíduos. Desta forma também fica evidente a dinâmica de inclusão de novos machos a partir da sua emergência, como também observado por YounG \& Thomason (1975) para Heliconius charitonia (Linnaeus, 1767). Indivíduos mais velhos, com soltura superior aos de sete dias não foram recapturados.

MALLET (1986) quando analisa a questão gregarismo, sugere também a hipótese do favorecimento do acasalamento, embora raro, já que em poleiros de Heliconius podem ser encontrados ambos os sexos.

LOPES \& DE MARCO (2000), discutem a agregação de machos de uma espécie em uma determinada área, como "lek", onde os machos permanecem se exibindo e guardando posições, esses locais são visitados por fêmeas com o único propósito de copular. BAKER (1983), propõem que nos "leks" os machos em agregações são mais atraentes do que os solitários; em uma agregação existem possibilidades de escolha para as fêmeas embora a pressão de predação favoreça os "leks" pois potencializa a percepção dos predadores. Neste estudo com A. surima surima as agregações só foram constatadas entre machos, sem a visita de fêmeas a estes locais. Possivelmente o comportamento de acasalamento das espécies de Actinote possa ter alguma influência na ausência de fêmeas nas agregações já que não há corte e sim captura, com colocação de tampão genital após a primeira cópula de um macho, defendendo o material genético contra a competição de outros machos, ou seja, uma forma simplificada de defesa de um recurso (BAKER 1983, PALUCH et al. 2003).

Também segundo MALlet (1986) o poleiro poderia funcionar como centro de informação, podendo servir para um indivíduo conduzir o outro até uma fonte de alimento, porém não há dados suficientes, nas observações com Actinote que possam corroborar esta hipótese. Em A. surima surima os poleiros registrados foram formados entre cinco e $30 \mathrm{~m}$ da fonte de alimento, flores de Asteraceae, indicando apenas uma tendência desta espécie em formar as suas agregações próximas ao alimento. Durante o

Revista Brasileira de Zoologia 22 (2): 410-418, junho 2005 

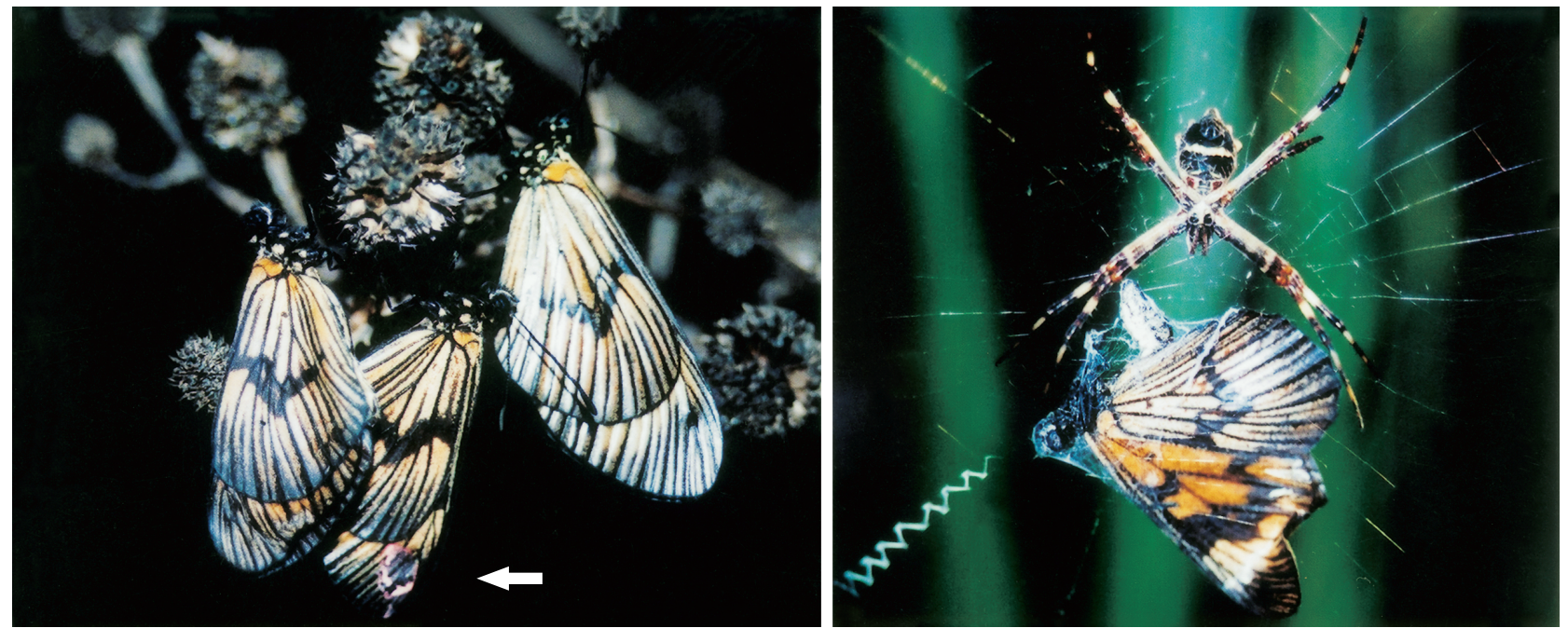

Figuras 5-6. Actinote surima surima: (5) grupo de três indivíduos machos, detalhe da marcação por grupos (ver seta); (6) indivíduo macho predado por Argiope argentata.

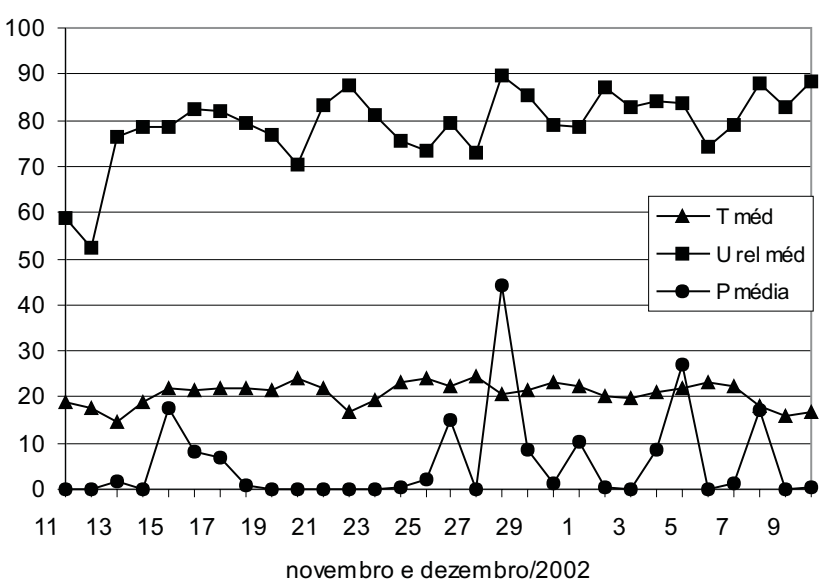

Figura 7. Temperatura, umidade relativa média e precipitação diária em Curitiba, Paraná, durante o experimento. (T méd) Temperatura média, (U rel méd): umidade relativa média, ( $\mathrm{P}$ méd) precipitação média.

dia os indivíduos machos foram observados procurando alimento isoladamente, ou defendendo os seus territórios sendo este um dos únicos momentos em que um indivíduo "segue" o outro, além dos ataques às fêmeas para o acasalamento, porém experimentos em áreas maiores deverão ser realizados para testar a possível validade da formação de um centro de informação.

ROCHA \& DUARTE (2001) relatam a competição pelos recursos florais de Aechmea gracilis Lindman (Bromeliaceae, Bromelioidea) entre Heliconius ethilla narcaea Godart, 1819 e Heliconius sara apseudes (Hübner, [1813]), sendo a primeira mais agressiva nessa exploração, este tipo de território defendido é classificado por LOPES \& DE MARCO (2000) como território com recurso onde não há nenhuma dúvida sobre o que se esta defendendo. Porém, os machos de $A$. surima surima não desenvolvem o comportamento de competições intra ou interespecifica por recursos florais, sendo que as fêmeas quando nas flores podem ser atacadas por machos, com o intuito de cópula; a aproximação entre machos não resulta em agressividade, sendo possível observar vários em um mesmo capitulo de Asteraceae, sem qualquer ação agressiva.

Das dez espécies de Actinote listadas por Mielke (1994): A. pellenea pellenea Hübner, [1821]; A. alalia (C. Felder \& R. Felder, 1860); A. mamita mitama (Schaus, 1902); A. surima surima (Schaus, 1902); A. carycina Jordan, 1913; A. parapheles Jordan, 1913; A. melanisans Oberthür, 1917; A. genitrix D'Almeida, 1922; A. dalmeidai Francini, 1996 e A. catarina Penz, 1996, além de $A$. pyrrha (Fabricius, 1775); A. brylla Oberthür, 1917; A. rhodope D'Almeida, 1923 e A. discrepans D'Almeida, 1958, todas foram avistadas forrageando somente em flores, principalmente de Asteraceae, não sendo encontradas sobre lama, carcaças ou excrementos de animais.

Outra hipótese citada por Mallet (1986), a da saciedade dos predadores visuais, parece plausível tendo em vista que algumas espécies de Actinote são de coloração aposemática e impalátaveis, assim como os Heliconiini. Com toxicidade resultante de alcalóides pirrolizidínicos e forte cianogênese detectados em todos os estágios, Actinote surima surima está integrada em um dos complexos miméticos müllerianos do gênero, o "complexo mimético alalia" (Brown \& Francini 1990, Penz \& FRANCINI 1996).

Provavelmente um predador inexperiente pode atacar alguns indivíduos do poleiro pela primeira vez, mas em um segundo encontro aprenderá a evitá-los como alimento. Em

Revista Brasileira de Zoologia 22 (2): 410-418, junho 2005 
observações de campo até o momento, não foi registrado nenhum ataque de predadores a esses poleiros.

Quanto à questão de evitar a perturbação por grandes animais noturnos não insetívoros, uma quarta hipótese, não parece adequada para $A$. surima surima, pois os seus poleiros não são mantidos de um dia para o outro, ocorrendo sempre à escolha de um novo local para a formação da agregação, em Heliconius um poleiro encontrado por um indivíduo pode significar um local seguro onde várias borboletas já passaram algumas noites. Em A. surima surima foi encontrado um poleiro com 11 indivíduos sobre um arbusto seco sem folhas a $40 \mathrm{~cm}$ do solo (Fig. 2), sendo um local totalmente desprotegido e facilmente destruído de maneira acidental por algum animal noturno; outro ponto vulnerável na realização de vôos próximos ao solo para realização de poleiros envolve as várias possibilidades das borboletas serem interceptadas por teias de aracnídeos como Argiope spp. (Araneidae: Araneae), que formam suas teias em bromeliáceas de solo, onde se registrou dois poleiros de A. surima surima (Fig. 3) além de um individuo macho predado por Argiope argentata (Fabricius, 1775) (Fig. 6). Alguns poleiros registrados em árvores, nas folhas de Schinus terebinthifolius Raddi (aroeira-vermelha) (Anacardiaceae), também não devem ser considerados como locais seguros pois estão expostos à ação de predadores invertebrados como formigas e outras aranhas.

Actinote carycina, A. melanisans, A. genitrix e A. rhodope registradas no local durante o experimento, não apresentam formações de poleiros e se abrigam nas árvores dos capões, pois voam na direção destas próximo ao horário em que ocorre a agregação de A.surima surima. Experimentos mais detalhados devem ser desenvolvidos em áreas onde ocorram grandes populações destas espécies, pois no local do experimento a população predominante foi de A. surima surima certamente pela abundância da planta hospedeira.

Quanto ao gregarismo larval, as únicas espécies que assim se mostraram até o último estádio entre as cinco citadas para a área do experimento foram A. genitrix e A. rhodope, sendo que entre outubro/novembro de 1998 coletou-se no local do experimento uma formação gregária de 33 larvas no último estádio sobre Mikania hirsutissima DC, e obteve-se indivíduos das duas espécies compondo uma formação larval interespecifica. Fenotipicamente as larvas são semelhantes na coloração marrom castanho do corpo, larvópodos, placas pronotal e suranal, escolos, no padrão castanho enegrecido da cabeça e das pernas torácicas, nas mensurações e distribuição dos escolos do corpo, porém a planta hospedeira de $A$. rhodope em Curitiba e cercanias é Mikania guaco Humb. \& Bonpl., sendo que o desenvolvimento larval de algumas espécies pode ser completado com planta hospedeira "alternativa".

O estudo de Actinote surima surima com marcações individuais e por grupos permitiu constatar que novos poleiros são escolhidos todas as tardes; estes não são mantidos entre os mesmos grupos de machos, havendo permuta aleatória entre eles, porém nada impede que um determinado número de machos possa pernoitar mais de uma vez juntos; aparentemente não há uma preferência por local e sim pelo substrato (galhos secos sem folhas); não ocorrem agregações interespecíficas; todos as agregações observadas $(\mathrm{n}=11)$ foram formadas somente por machos a partir das 16:00 h (17:00 h horário de verão - Brasília); os machos mais "velhos", com sete dias, foram recapturados ativos no ambiente e possivelmente ainda defendam seus territórios e participem das agregações noturnas.

Assim como o comportamento das espécies de Heliconius, A. surima surima também apresenta uma complexidade a ser elucidada. Existem poucos dados em literatura sobre comportamento e hábitos dos adultos de Actinote, porém alguns dados aqui levantados podem vir a contribuir para a realização de trabalhos comparativos, para um melhor entendimento das espécies neotropicais, podendo no futuro contribuir diretamente na fundamentação da tribo Acraeini.

\section{REFERÊNCIAS BIBLIOGRÁFICAS}

Alcock, J. 1987. The mating system of three territorial butterflies in Costa Rica. Journal of Research on the Lepidoptera, Santa Barbara, 26: 89-97.

BAKER, R.R. 1983. Insect territoriality. Annual Review of Entomology, Palo Alto, 28: 65-89.

Biezanko, C.M.; A. Rufinelli \& D. Link. 1974. Plantas e otras substancias alimenticias de las orugas de los lepidopteros Urugayos. Revista do Centro de Ciências Rurais, Santa Maria, 4 (2):107-148.

Brown, K.S. \& R.B. Francini. 1990. Evolutionary strategies of chemical defense in aposematic butterflies: cyanogenesis in Asteraceae-feeding American Acraeinae. Chemoecology, Berlin, 1: 52-56.

Carpenter, G.D.H. 1931. Acraeinae butteflies congregating in a small area for the night's rest. Proceedings of the Royal Entomological Society of London 6: 71.

Freitas, A.V.L.; W.W. Benson; O.J. Marini-Filho \& R.M. Carvalho. 1997. Territoriality by the dawn's early light: the Neotropical owl butterfly Caligo idomenaeus (Nymphalidae: Brassolinae). Journal of Research on the Lepidoptera, Beverly Hills, 34: 14-20.

LAMAS, G. 2004. Heliconiinae, p. 262-274. In: G. LAMAS (Ed.). Checklist: Part 4A, Hesperioidea - Papilionoidea, 439 p. In: J.B. HeppNer (Ed). Atlas of Neotropical Lepidoptera. Gainesville, Association for Tropical Lepidoptera, Scientific Publishers.

Lopes, F.S. \& P. DE Marco Jr. 2000. Comportamento territorial em insetos: aspectos e estudos de casos, p.193-222. In: R.P. Martins; T.M. Lewinsohn \& M.S. Barbeitos (Eds). Ecologia e comportamento de insetos. Rio de Janeiro, Oecologia Brasiliensis, vol. 8, 435p.

Mallet, J. 1986. Gregarious Roosting and Home Range in Heliconius Butterflies. National Geographic Research, London, 2 (2): 198-205.

Marshall, A.K. 1901. On the female pouch in Acraea. Entomo- 
logy, London, 34: 73-75.

MielKe, C.G.C. 1994. Papilionoidea e Hesperioidea (Lepidoptera) de Curitiba e seus arredores, Paraná, Brasil, com notas taxonômicas sobre Hesperiidae. Revista Brasileira de Zoologia, Curitiba, 11 (4): 759-776.

Morton, A.C. 1984. The effects of Marking and Handling on Recapture Frequencies of Butterflies, p. 55-58. In: R.I. VANEWright \& P.R. Ackery (Eds). The Biology of Butterflies. London, Academic Press, 429p.

Paluch, M.; M.M. Casagrande \& O.H.H. Mielke. 1999. Estágios imaturos de Actinote surima (Schaus) (Lepidoptera, Nymphalidae, Acraeinae). Revista Brasileira de Zoologia, Curitiba, 16 (Supl. 2): 129-140.

Paluch, M.; M.M. Casagrande \& O.H.H. Mielke. 2001. Estágios imaturos de Actinote carycina Jordan (Lepidoptera, Nymphalidae, Acraeinae). Revista Brasileira de Zoología, Curitiba, 18 (3): 883-896.

Paluch, M.; M.M. Casagrande \& O.H.H. Mielke. 2003. Tampão genital de Actinote Hübner, como caráter taxonômico. (Lepidoptera, Nymphalidae, Acraeinae). Revista Brasileira de Entomologia, Curitiba, 47 (4): 573-580.

Penz, C.M. \& R.B. Francini. 1996. New species of Actinote Hübner (Nymphalidae: Acraeinae) from southeastern Brazil. Journal of the Lepidopterists' Society, Lawrence, 50 (4): 309-320.

Penz, C.M. \& D. Peggie. 2003. Phylogenetic relationships among Heliconiinae genera based on morphology (Lepidoptera: Nymphalidae). Systematic Entomology, London, 28: 451479.

Rocha, C.F. \& M. DuARTE. 2001. Territorial-like defensive behavior of floral resources by Heliconius ethila narcaea Godart over $H$. sara apseudes (Hübner) (Lepidoptera, Nymphalidae, Heliconiinae). Revista Brasileira de Zoologia, Curitiba, 18 (Supl. 1): 323-328.

Ruszczyk, A.; P.C. Motta; R.L. Barros \& A.M. Araújo. 2004. Ecological correlates of polyphenism and gregarious roosting in the grass yellow butterfly Eurema elathea (Pieridae). Brazilian Journal Biology, São Carlos, 64 (1): 151-164.

Sourakov, A. \& T.C. Emmel. 1997. Mating habits in the genus Acraea, with a possible explanation for monosexual populations (Lepidoptera: Nymphalidae: Acraeinae). Tropical Lepidoptera, Gainesville, 8 (Supl. 3): 33-36.

Young, A.M. \& J.H. Thomason. 1975. Notes on communal roosting of Heliconius charitonius (Nymphalidae) in Costa Rica. Journal of the Lepidopterists' Society, Lawrence, 29 (4): 243-255.

Recebido em 09.III.2004; aceito em 23.V.2005. 